\title{
Distributor effects near the bottom region of turbulent fluidized beds
}

\author{
Celia Sobrino ${ }^{\mathrm{a}, *}$, Naoko Ellis $^{\mathrm{b}}$, Mercedes de Vega ${ }^{\mathrm{a}}$ \\ a Departamento de Ingeniería Térmica y de Fluidos, Universidad Carlos III, Madrid, Spain \\ ${ }^{\mathrm{b}}$ University of British Columbia, Department of Chemical and Biological Engineering, Vancouver, BC, Canada
}

\begin{abstract}
A B S T R A C T
The distributor plate effects on the hydrodynamic characteristics of turbulent fluidized beds are investigated by obtaining measurements of pressure and radial voidage profiles in a column diameter of $0.29 \mathrm{~m}$ with Group A particles using bubble bubble cap or perforated plate distributors. Distributor pressure drop measurements between the two distributors are compared with the theoretical estimations while the influence of the mass inventory is studied. Comparison is established for the transition velocity from bubbling to turbulent regime, $U_{c}$, deduced from the pressure fluctuations in the bed using gauge pressure measurements. The effect of the distributor on the flow structure near the bottom region of the bed is studied using differential and gauge pressure transducers located at different axial positions along the bed. The radial voidage profile in the bed is also measured using optical fiber probes, which provide local measurements of the voidage at different heights above the distributor. The distributor plate has a significant effect on the bed hydrodynamics. Owing to the jetting caused by the perforated plate distributor, earlier onset of the transition to the turbulent fluidization flow regime was observed. Moreover, increased carry over for the perforated plate compared with the bubble caps has been confirmed. The results have highlighted the influence of the distributor plate on the fluidized bed hydrodynamics which has consequences in terms of comparing experimental and simulation results between different distributor plates.
\end{abstract}

\section{Introduction}

A good understanding of the flow structure in fluidized beds is of great importance to fluidized beds design, scale up and reactor study. Many works [1 4 ] have been aimed to develop a good understanding of the flow structure in circulating fluidized beds (CFB). The axial solids distribution in a riser of a CFB is generally characterized by a dense region, transition region, dilute region and exit region. The radial flow structure is characterized by a core annulus flow: a dilute core region, in the central portion of the riser surrounded by a dense annular layer of solids at the wall. A few papers were published regarding the flow structure near the bottom zone of circulating fluidized beds [5 7]. However, very little work has been reported on the influence of the bed support $[8,6]$ despite many data being collected by industry on the design of distributors for specific purposes. The design and effects of distributor type have been extensively discussed in the past for bubbling fluidized beds, while mainly pertaining to perforated and porous plates or novel designs [9 13]. However, to the authors' knowledge, there are no previous published investigations comparing the performance of perforated plate and bubble cap distributors in the dense region of CFB, or in a turbulent fluidization flow regime. Furthermore, it has been found

\footnotetext{
* Corresponding author. Tel.: +34 916248884; fax: +34 916249430.

E-mail address: csobrino@ing.uc3m.es (C. Sobrino).
}

that the distributor design affects the behaviour of the bed over most of its height [14]. The knowledge on the effects of these two types of distributor to the flow structure is of particular interest to scale up aimed works, since most industrial and pilot scale plants employ bubble cap distributors, while most lab scale and academic columns operate with perforated plate distributors.

Distributor pressure drop, axial pressure profiles along the bed and circulation patterns are often studied in order to explore the bottom zone of circulating fluidized beds. Sathiyamoorthy and Horio [15] studied the influence of the pressure drop and aspect ratio on the uniformity of fluidization. Guo et al. [8], on the other hand, measured the flow rate of gas in the bubble caps of a riser with a cross section of $0.3 \times 1 \mathrm{~m}$, in order to characterize the flow maldistribution. Axial pressure profiles have also been used to demarcate the height of the bottom zone and to study the flow structure in this region [5,7]. Several works have reported information about solids concentration distribution and particle velocities in the CFB bottom zone $[6,7,16]$. Details on the local void behaviour provide crucial information for the reactor performance evaluation, as void characteristics are the main controlling parameter in solid mixing and gas solid contact. Further more, previous works have reported on the time mean radial voidage profiles in fluidized beds for Group A particles for columns of different diameters [17,18].

In this paper, the effect of the distributor type on the flow structure near the bottom region of a turbulent fluidized bed is revealed for the first time. In depth analysis from the differential and gauge pressure 
a

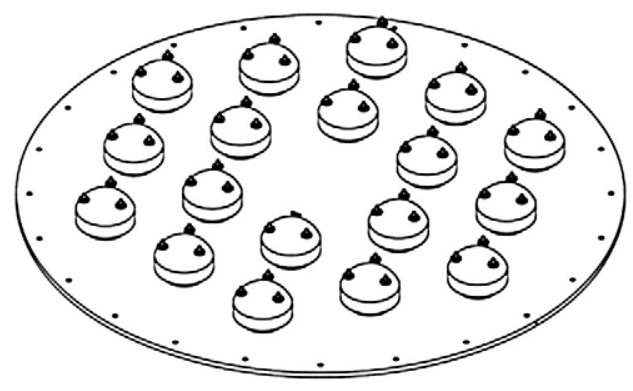

b

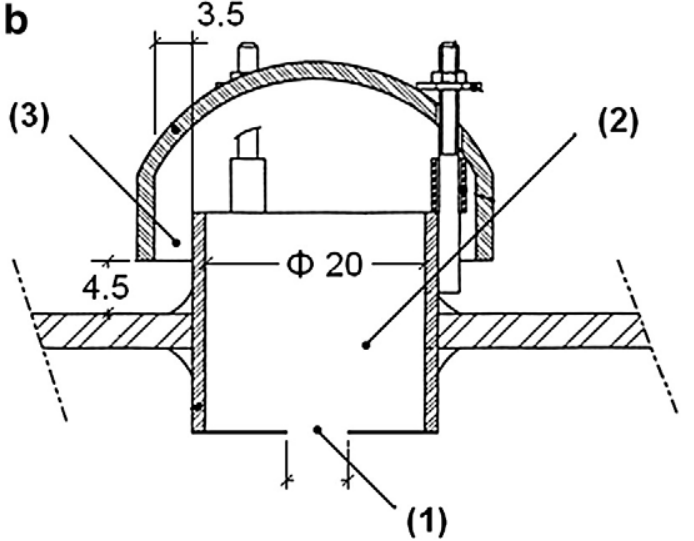

Fig. 1. a) Schematic diagram showing bubble caps on distributor of $0.29 \mathrm{~m}$ diameter column. b) Schematic of a cap of the bubble-cap distributor. Dimensions in mm.

measurements and local voidage measurements obtained using optical probes are performed to characterize the hydrodynamics.

\section{Theory}

\subsection{Distributor pressure drop}

The pressure drop across the distributor can be obtained by applying the Bernoulli equation between two points, upstream and downstream of the distributor plate and adding the frictional losses:

$p_{1}+\frac{1}{2} \rho v_{1}^{2} \quad p_{2}+\frac{1}{2} \rho v_{2}^{2}+\sum K \frac{1}{2} \rho v_{\text {base }}^{2}$

where $p_{1}$ and $p_{2}$, and $v_{1}$ and $v_{2}$ are the static pressures and velocities upstream and downstream of the distributor, respectively. $K$ is the flow resistance coefficient based on the smallest cross sectional area of the component; hence, it has the higher velocity in the component

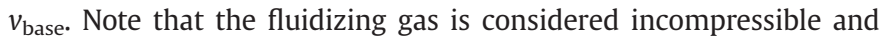
wall friction pressure drop is neglected. The contribution of the kinetic energy term to the measured pressure can be neglected; therefore, the pressure drop across the distributor can be estimated by:

$\Delta p_{\mathrm{d}} \quad \sum K \frac{1}{2} \rho v_{\text {base }}^{2}$.

\subsection{Perforated plate pressure drop}

The perforated plate distributor used in the experiments was provided with a mesh to prevent the particles falling in the plenum chamber. This mesh significantly increases the pressure drop across the distributor plate; thus, the flow resistance in the mesh requires to be calculated. The pressure drop in the perforated plate will be estimated as following:

$\Delta p_{\mathrm{p}, \mathrm{d}} \quad K_{\mathrm{p}, \text { orifice }} \frac{1}{2} \rho_{\mathrm{g}} U_{\mathrm{p}, \text { orifice }}^{2}+K_{\text {mesh }} \frac{1}{2} \rho_{\mathrm{g}} U_{\text {mesh }}^{2}$.

Rearranging, the above equation can be written as:

$\Delta p_{\mathrm{p}, \mathrm{d}} \quad \frac{1}{2} \rho_{\mathrm{g}} U^{2}\left[K_{\mathrm{p}, \text { orifice }}\left(\frac{A}{A_{\mathrm{p}, \text { orifice }}}\right)^{2}+K_{\text {mesh }}\left(\frac{A}{A_{\text {mesh }}}\right)^{2}\right]$.

Note that there are two different perforated plates sandwiching the mesh. The installation of two grids close to each other should not lead to an increase in flow resistance, but rather results in a grid of double thickness in the flow direction [19].
The pressure drop in a perforated plate is usually calculated in fluidized beds literature as [9]:

$U_{\text {orifice }} \quad C_{\mathrm{d}} \sqrt{\frac{2 \Delta p_{\mathrm{d}}}{\rho_{\mathrm{g}}}}$

where $C_{\mathrm{d}}$ is the discharge coefficient of an orifice. Thus,

Korifice $\frac{1}{C_{\mathrm{d}}^{2}}$.

For the entrance into a straight tube through a perforated plate with thick orifices Idelchik [19] gives:

$$
\begin{aligned}
& K_{\mathrm{p}, \text { orifice }}\left(0.5+\tau /\left(1 \frac{A_{\mathrm{p}, \text { orifice }}}{A}\right)\right)\left(1 \frac{A_{\mathrm{p}, \text { orifice }}}{A}\right) \\
&+\left(1 \frac{A_{\mathrm{p}, \text { orifice }}}{A}\right)^{2} \text { for } \operatorname{Re}_{\text {orifice }}>10^{4} \quad 10^{5}
\end{aligned}
$$

where $R e_{\text {orifice }} \frac{U_{\text {orifice }} d_{\text {orifice }} \rho_{g}}{\mu_{g}}$. The thickness parameter $\tau=0$ for thick plates $\left(t_{\mathrm{p}} / d_{\mathrm{p}, \text { orifice }}>2\right)$ and $\tau=1.35$ for thin plates $\left(t_{\mathrm{p}} / d_{\mathrm{p}, \text { orifice }}=0 \quad 0.015\right)$.

The second term of Eq. (4) is the pressure drop caused by the presence of the mesh. For the flow resistance coefficient of a circular metal wire screen Idelchik [19] gives:

$K_{\text {mesh }}=k_{R e}^{\prime}\left[1.3\left(1-\frac{A_{\text {mesh }}}{A}\right)+\left(\frac{A}{A_{\text {mesh }}}-1\right)^{2}\right]\left(\frac{A_{\text {mesh }}}{A}\right)^{2}$ for $50<R e_{\text {mesh }}<1000$

where $R e_{\text {mesh }} \quad \frac{\rho_{\mathrm{g}} U_{\text {mesh }} d_{\text {mesh }}}{\mu}$ and $d_{\text {mesh }}$ is the mesh opening. In this case $k_{R e}^{\prime} \approx 1.13\left(R e_{\text {mesh }} \approx 150\right)$.

\subsection{Bubble cap distributor pressure drop}

Fig. 1 shows a schematic of a cap of the distributor. Main pressure drop in the bubble caps of the distributor occurs at the entrance orifice (indicated as section (1) in Fig. 1b) and in the contraction (section 3 in Fig. 1b). The cylindrical volume (section 2 in Fig. 1b) can be considered a stagnant volume.

In terms of the superficial gas velocity the pressure drop in the bubble cap distributor is given by:

$$
\Delta p_{\mathrm{c}, \mathrm{d}} \quad \frac{1}{2} \rho_{\mathrm{g}} U^{2}\left[K_{\mathrm{c}, \text { orifice }}\left(\frac{A}{A_{\mathrm{c}, \text { orifice }}}\right)^{2}+K_{\text {cap }}\left(\frac{A}{A_{\text {cap }}}\right)^{2}\right] .
$$


For orifices or perforated plate installed in transition section Idelchik [19] gives:

$$
\begin{aligned}
& K_{\mathrm{c}, \text { orifice }} 0.5\left(1 \frac{A_{\mathrm{c}, \text { orifice }}}{A}\right)+\left(1 \frac{A_{\mathrm{c}, \text { orifice }}}{A_{2}}\right)^{2}+\tau \sqrt{1} \frac{A_{\mathrm{c}, \text { orifice }}}{A_{2}} \\
& \times\left(1 \frac{A_{\mathrm{c}, \text { orifice }}}{A_{2}}\right) \text { for } R e_{\text {orifice }}>10^{4} 10^{5} .
\end{aligned}
$$

Note that bubble cap distributors have a slightly smaller pressure drop than the perforated plate, provided the same open area. This is due to the installed cap over each orifice reducing the flow resistance since the flow expansion from the orifice undergoes two stages, i.e., from the orifice to the cap and then from the cap to the column. The area $A_{2}$ is the cross sectional area of the cylindrical section 2 in Fig. 1a. The flow resistance coefficient of the contraction (section 2 in Fig. 1b) can be calculated as a labyrinth with flow passage from one volume into another through a 90 turn. For this coefficient Idelchik [19] gives:

$K_{\text {cap }} \quad 3.7$.

$A_{\text {cap }}$ in Eq. (10) is the cross sectional area of section 3 in Fig. 1b.

\section{Experiments}

Experiments were carried out in a $0.29 \mathrm{~m}$ diameter and $4.5 \mathrm{~m}$ tall Plexiglas column. The disengaging section at the top of the column, expanded to $0.4 \mathrm{~m} \mathrm{ID}$, abruptly converges to a $0.1 \mathrm{~m}$ exit duct connected to two external cyclones in series. Fluidizing air is supplied by a Roots blower with a maximum capacity of $425 \mathrm{~N} \mathrm{~m}^{3}$ at $65 \mathrm{kPa}$. The solid re entry level of the return leg is at $0.0510 .81 \mathrm{~m}$ above the distributor. Each return leg is equipped with a flapper valve to prevent gas from escaping up the standpipe. The mass solid flux varies between 0.1 and $1.0 \mathrm{~kg} / \mathrm{m}^{2} \mathrm{~s}$ for $H_{0}$ range of 0.4 to $1.3 \mathrm{~m}$ and $U$ of 0.5 to $0.8 \mathrm{~m} / \mathrm{s}$. Further details on the solid circulation flux can be found elsewhere [20]. Fig. 2 illustrates the fluidized bed column. The solids used in the study were

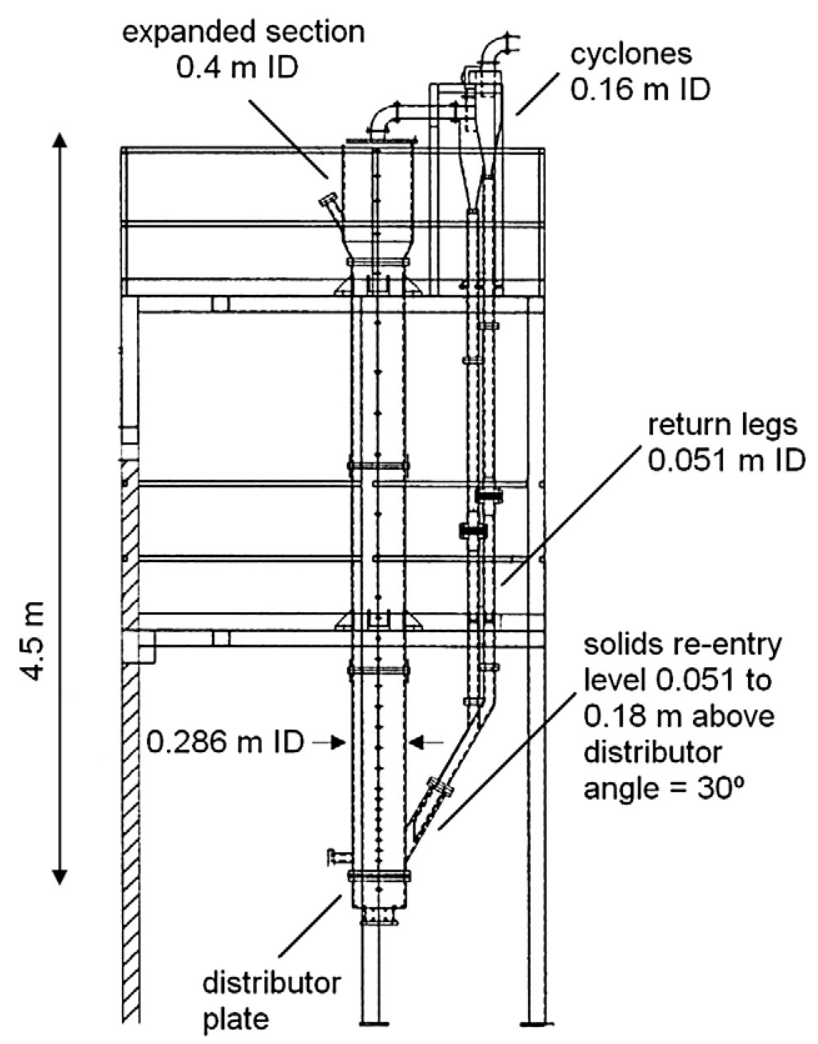

Fig. 2. Schematic of $0.29 \mathrm{~m}$ diameter, $4.5 \mathrm{~m}$ tall fluidization column at UBC.

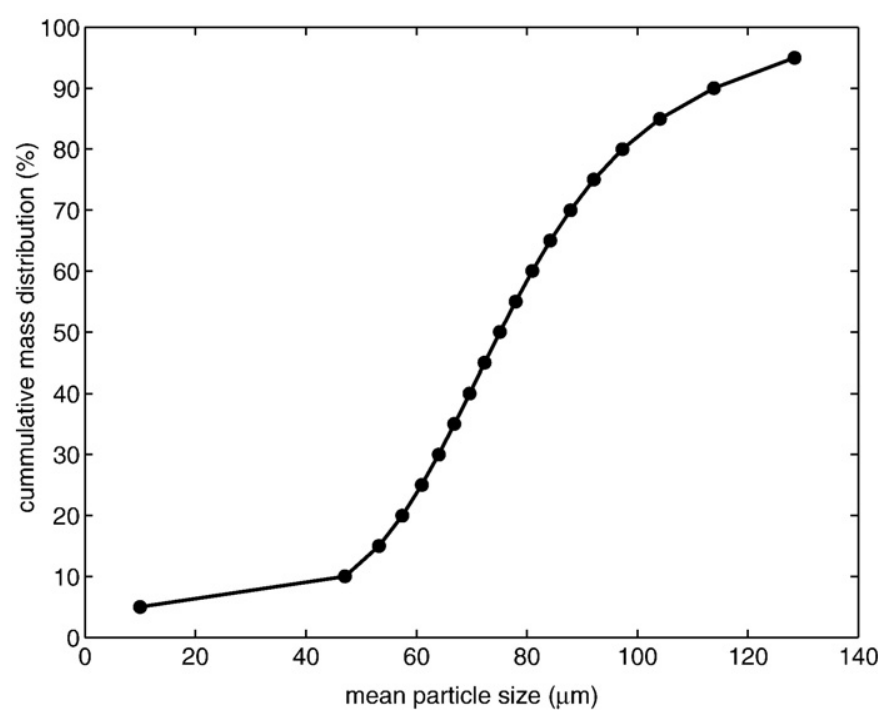

Fig. 3. Particle size distribution of spent FCC particles.

FCC particles with $1560 \mathrm{~kg} / \mathrm{m}^{3}$ density and $78 \mu \mathrm{m}$ mean diameter. Fig. 3 shows the cumulative size distribution of the FCC sample. The minimum fluidization velocity of the bed was $U_{\mathrm{mf}}=0.007 \mathrm{~m} / \mathrm{s}$. The column is equipped with 58 sampling ports and it was instrumented for this study with 9 differential pressure transducer and 8 gauge pressure transducers (OMEGA PX140) placed along the column length. Pressure taps were mounted flush with the wall of the column with $38 \mu \mathrm{m}$ mesh stainless steel screens glued over the entrance to prevent solids from entering the pressure sensing lines. Flow was measured with an orifice flowmeter installed in the air line. $\mathrm{T}$ type thermocouples were used to measure temperature in the orifice flowmeter, in the plenum chamber and in the bed for density calculation purpose.

Reflective type optical fiber probes (PC 4 Powder Voidmeter) developed at UBC and manufactured by the Institute of Chemical Metallurgy at Beijing, China, were used for measuring local voidage. Each probe contains a bundle of fibers projecting light onto a swarm of particles interspersed with light receiving fibers, which measure the intensity of the light reflected from the particles. The bundle diameter is $4 \mathrm{~mm}$, its length is $600 \mathrm{~mm}$, and the individual fiber diameter is $15 \mu \mathrm{m}$. The fibers are arranged in an alternating array of emitting and receiving layers. Because the particle diameter is much smaller than the bundle diameter, light is reflected by many particles in the measurement volume, allowing the probe to detect the instantaneous local solids volume concentration from the output voltage, after suitable calibration. The measurement system includes also, a light source, a photomultiplier, an A/D converter and a data acquisition board installed in the PC. Before and after each set of runs, the voidmeter was calibrated against a dense bed (to give $\sim 5 \mathrm{~V}$ ) and a bed of black particles to prevent reflection of light, representing the no solid condition (set at $\sim 0 \mathrm{~V}$ ). Linearity was then assumed to be valid for voidages between these two limits. The calibration equation was:

$\frac{1 \varepsilon}{1 \varepsilon_{\mathrm{mf}}} \quad \frac{V V_{0}}{V_{\mathrm{mf}} V_{0}}$

where $V_{0}$ is the voltage signal obtained from the black particles bed where negligible light is reflected, representing a voidage of 1 , and $V_{\mathrm{mf}}$ is the signal when the probe is immersed in a container of static solids representing closely the voidage at minimum fluidization $\left(\varepsilon_{\mathrm{mf}}=0.45\right)$. A quartz glass window was used to cover the probe tip in order to keep the signal intensity always below the maximum reference intensity $[21,22]$. Pressure and voidage signals were logged into a computer via an A/D converter (DAS08 EXP32) installed in a PC and were recorded at $100 \mathrm{~Hz}$ for $100 \mathrm{~s}$ intervals using LABTECH data acquisition software. 


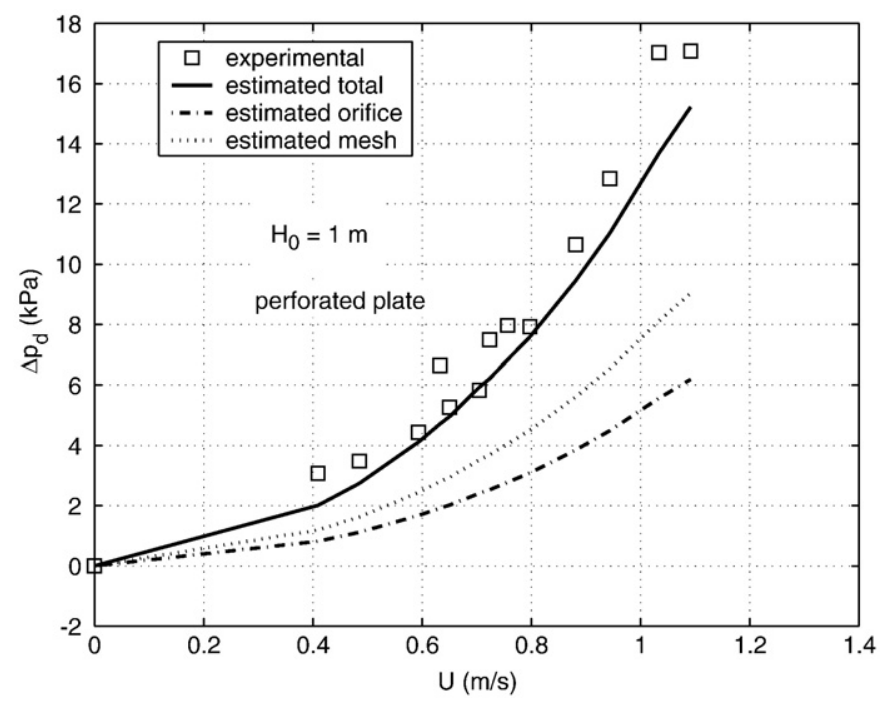

Fig. 4. Pressure drop across the perforated plate distributor.

Two different distributors are compared in this study: a bubble cap distributor and a perforated plate. The former is provided with 18 bubble caps. Details of the caps layout and dimensions are given in Fig. 1. The perforated plate distributor contains 98 holes of $5.6 \mathrm{~mm}$ diameter arranged in an equilateral triangular configuration with a $32 \mathrm{~mm}$ pitch. A second plate with the same number of holes of $6.4 \mathrm{~mm}$ diameter was located below the first plate with a $38 \mu \mathrm{m}$ stainless screen mesh (mesh No. 400, 36\% opened area) sandwiched between them to prevent particles from falling into the plenum chamber.

\section{Results and discussion}

\subsection{Distributor pressure drop}

Experimental distributor pressure drop in the perforated plate and the bubble cap distributor are compared with the theoretical calculation. As shown in Fig. 4, the experimental pressure drop across the perforated plate distributor was measured with an initial fixed bed height of $H_{0}=1 \mathrm{~m}$. The estimated pressure drop was calculated using Eq. (3) and compared to the experimental results along with the pressure drop contribution caused by the mesh and the plate itself. It can be observed that the main pressure drop in the distributor is due to the presence of the mesh. The opened area of the mesh employed in the experiments is $36 \%$. However the flow passage area is smaller (1.3\%) since the mesh is sandwiched between two plates, which have an opened area of $3.7 \%$.

Similar comparison is made for the pressure drop across the bubble cap distributor in Fig. 5. Excellent agreement with the theoretical calculations is indicated for superficial gas velocities of up to $0.5 \mathrm{~m} / \mathrm{s}$. It can also be observed that the resistance to flow caused by the cap itself is negligible in comparison with the resistance in the entrance orifice to the tuyere.

Fig. 6 compares the pressure drop in both distributors. The fitting line for each distributor has been obtained from the lineal regression of $U$ and $\sqrt{\frac{2 \Delta p_{\mathrm{d}}}{\rho_{\mathrm{g}}}}$, being $\Delta p_{\mathrm{d}}$ the measured pressure drop in the distributor, resulting:

$U \quad 0.0066 \sqrt{\frac{2 \Delta p_{\mathrm{d}, \text { perforated }}}{\rho_{\mathrm{g}}}}$

$U \quad 0.0067 \sqrt{\frac{2 \Delta p_{\mathrm{d}, \mathrm{caps}}}{\rho_{\mathrm{g}}} .}$

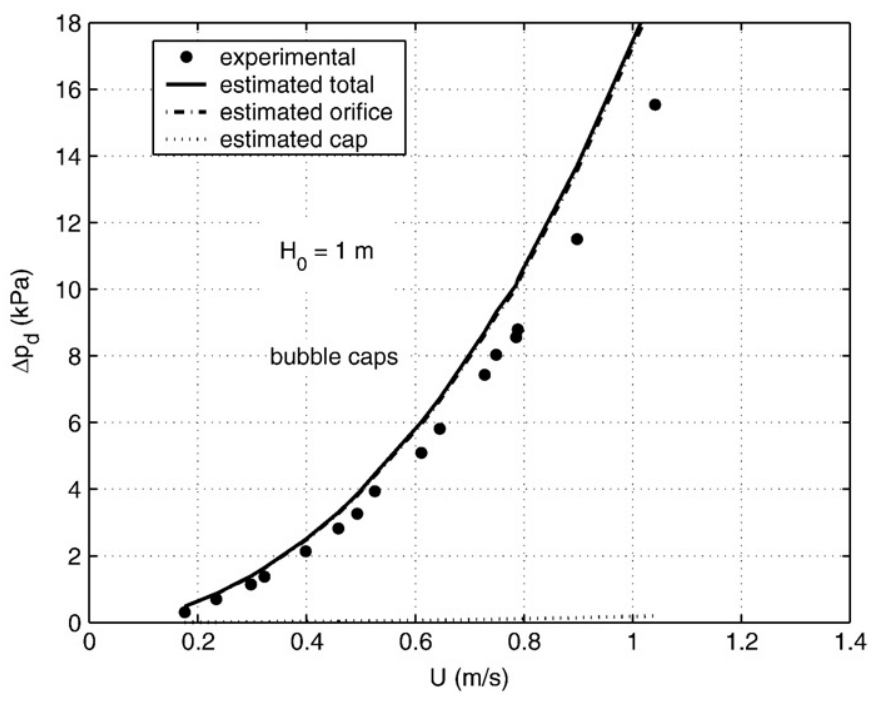

Fig. 5. Pressure drop across the bubble-cap distributor.

It is confirmed that the two distributors compared in this study present the same pressure drop.

The presence of the solids and the different mass inventory causes changes in the air density in the plenum chamber and the bed. Temperature in the plenum chamber and in the bed was measured in order to calculate the gas density.

The results are plotted against the superficial gas velocity in Fig. 7 for different mass inventories from both measurements at the plenum chamber and inside the bed. Measurements at the empty bed were also carried out in order to study the influence of the presence of the bed on the gas density. Previous investigators have reported the changes in the distributor pressure drop with the empty bed or in the presence of the bed [15]. However, as was observed in Fig. 7 the mass inventory does not have a significant influence on the gas density and hence the variations of the pressure drop are hardly noticeable, as can be seen in Fig. 8. Thus, the hypothesis of incompressibility of the fluidizing gas is deemed reasonable.

\subsection{Transition velocity}

The transition velocity, $U_{\mathrm{c}}$, is defined as the velocity at which the standard deviation of pressure fluctuations attains a maximum. Fig. 9

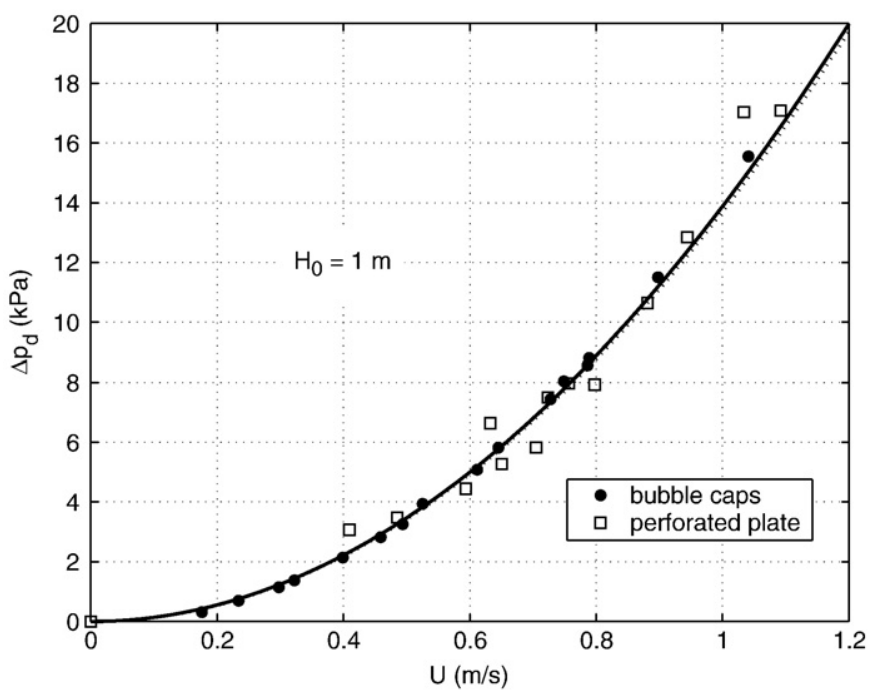

Fig. 6. Comparison of pressure drop in the two distributors in the presence of the bed material. 


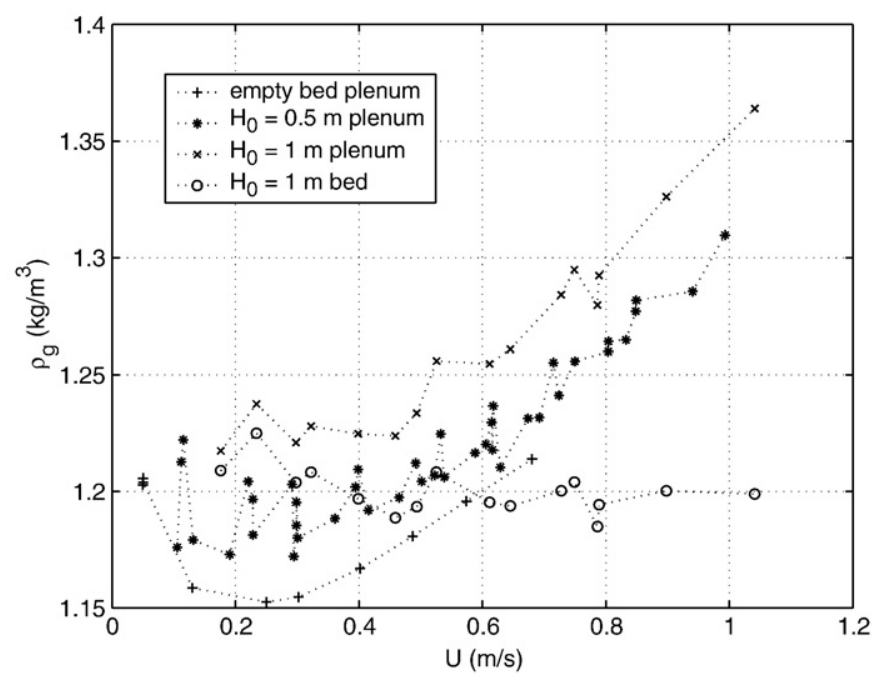

Fig. 7. Gas density against superficial gas velocity in the plenum chamber and inside the bed for different mass inventories.

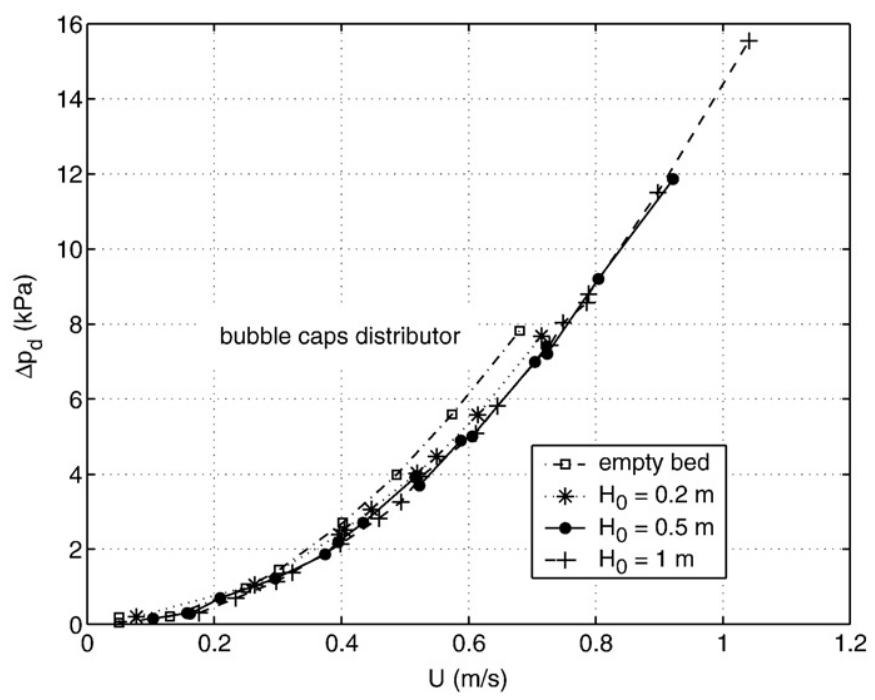

Fig. 8. Pressure drop across the bubble-cap distributor for different mass inventories. shows the estimation of this velocity for the two different types of distributor studied for $H_{0}=0.5 \mathrm{~m}$. The pressure has been measured at an axial distance of $0.21 \mathrm{~m}$ above the distributor using a gauge pressure transducer. Experimental data are plotted together with the second order polynomial curve that fits the data and error bound corresponding to a $95 \%$ confidence interval. $U_{\mathrm{c}}$ value has been found to be dependent of the axial position of the pressure probe and the type of pressure measurement, i.e., gauge or differential. Other investigators reported a decrease of the measured $U_{\mathrm{c}}$ value with increasing the axial position of the pressure probe [23], pointed out that is essential that the pressure probe be immersed in the bed at all times [24] and observed that the dependence on the pressure probes location was greater when using differential pressure measurements to determine $U_{\mathrm{c}}$ [16].

$U_{\mathrm{c}}$ is lower when operating the column with the perforated plate distributor compared to the bubble caps. This is likely due to the differences in void development in the bed. For $U_{\mathrm{c}}$ to be lower, voids created through the perforated plate will attain the maximum stable voids at lower superficial gas velocity. The absolute values of the standard deviation of the gauge pressure also indicate that the perforated plate creates smaller voids. It is suspected that the momentum of the jetting through the perforated plate distributor is large, and that the voids remain rather small compared to those created through bubble caps.

\subsection{Axial flow structure in the bottom region}

The axial pressure profiles near the bottom region of the bed are studied in Fig. 10. Higher pressure values are found for the perforated plate, indicating that voids are more frequent in this region [13]. This is confirmed by the voidage results. On the other hand the bed pressure drop in the dense bed is lower for the perforated plate although the theoretical pressure drop should be the same for both distributors, provided the same mass inventory. Thorpe et al. [25] interpreted this difference as being due to the mass of sand resting on the distributor plate and therefore not fluidized. They speculated that the height of the entry zone was proportional to this mass. This assumption indicates that a lower pressure drop in the dense bed for the perforated plate distributor leads to a higher height of the entry zone. Masters [26] also warned about the product that can remain static between the holes of perforated plate distributors.

The above is all consistent with the theory of the jets formed in the orifices of the air distributor, which will be discussed later.

Svensson et al. [5] defined the height of the dense bed as the level at which the axial pressure profiles start to deviate from the straight line. Fig. 10 shows these profiles for several gas velocities. To calculate the dense bed height linear fittings have been adjusted for axial

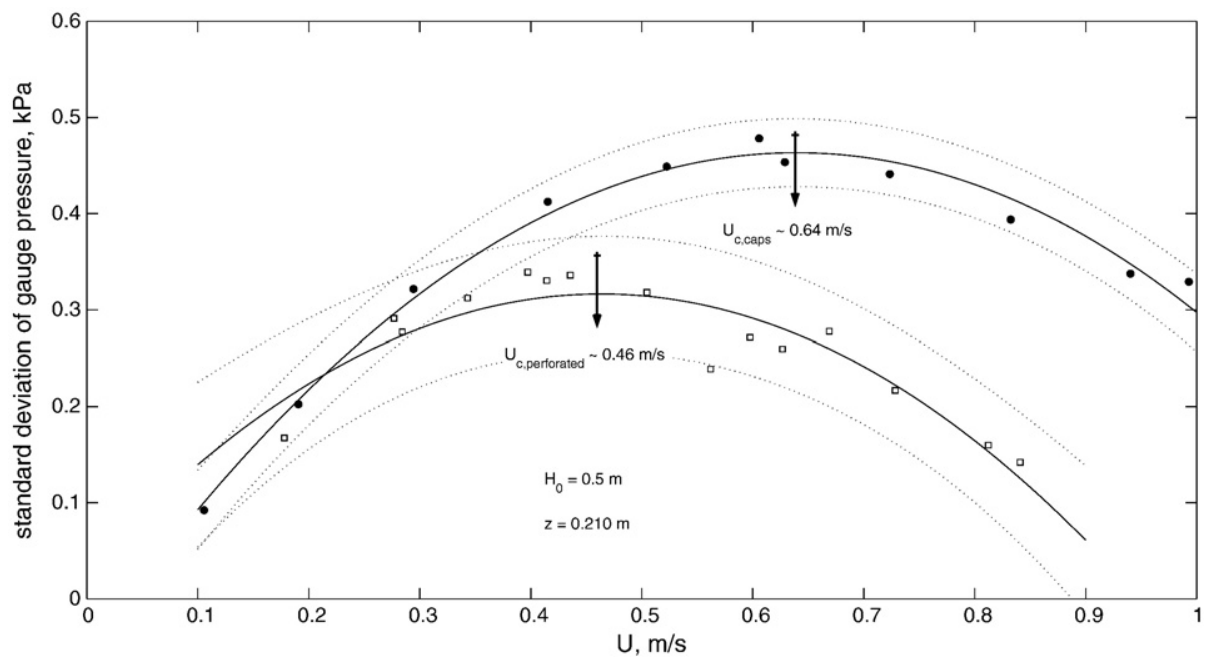

Fig. 9. $U_{\mathrm{c}}$ determination using the standard deviation of gauge pressure for $H_{0}=0.5 \mathrm{~m}$ and $z=0.210 \mathrm{~m}$ above the distributor. Filled circles: bubble cap. Squares: perforated plate. 


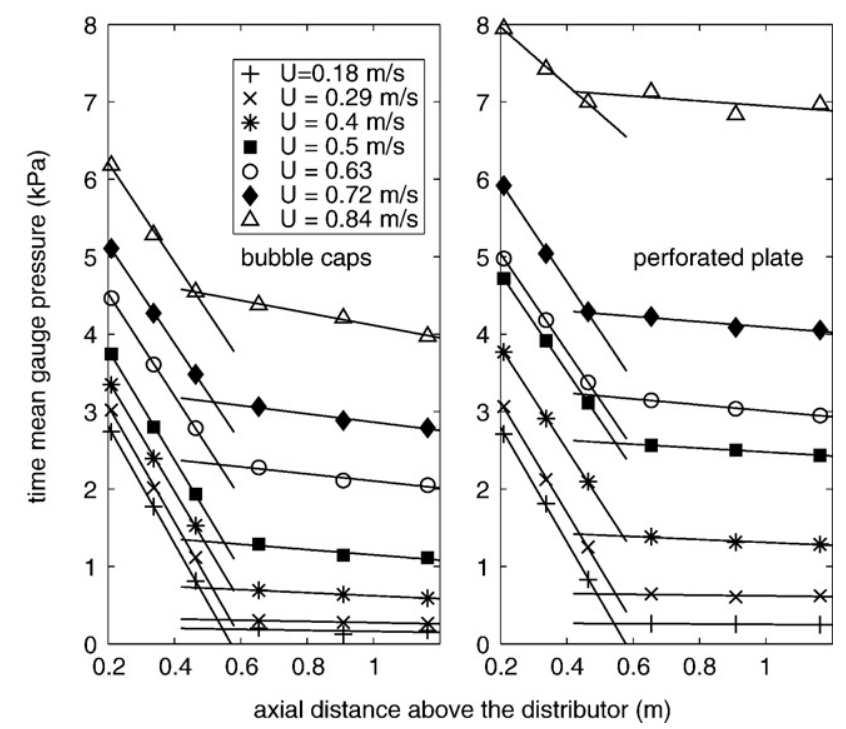

Fig. 10. Gauge pressure profile along the axial coordinate for different gas velocities for the two distributors. $H_{0}=0.5 \mathrm{~m}$. Uc, perforated $\sim 0.46 \mathrm{~m} / \mathrm{s}$. $U_{\mathrm{c}, \text { caps }} \sim 0.64 \mathrm{~m} / \mathrm{s}$.

profiles inside the bottom bed and in the transport zone. The intersection of both straight lines has been considered as the dense bed height. The dense bed height calculated this way is plotted against the superficial gas velocity in Fig. 11. A linear function has been fitted for velocities higher than $U_{\mathrm{c}}\left(U_{\mathrm{c}, \text { perforated }} \sim 0.46 \mathrm{~m} / \mathrm{s} . U_{\mathrm{c}, \text { caps }} \sim 0.64 \mathrm{~m} / \mathrm{s}\right)$, when the height of the dense bed starts to decrease. Error bounds corresponding to a $95 \%$ confidence interval are plot with the fitting lines. It can be observed that the bed expansion is very similar for both distributors for superficial gas velocities below $U_{\mathrm{c}}$. However the decrease of the dense bed height begins earlier for the perforated plate than the bubble caps as the superficial gas velocity is increased.

The transition to turbulent fluidization is caused by the beginning of the breakdown of bubbles [23], which was also observed in this study. Furthermore, the solids hold up in the freeboard and the amount of entrainment from the bed have influences during the transition from bubbling to transport [27]. In this study, the transport of solids from the dense phase to the free board begins to occur at lower gas velocity when the perforated plate distributor is used which is in accordance with the lower $U_{\mathrm{c}}$ found for the perforated plate distributor. This indicates that the rate of solids transferred from the

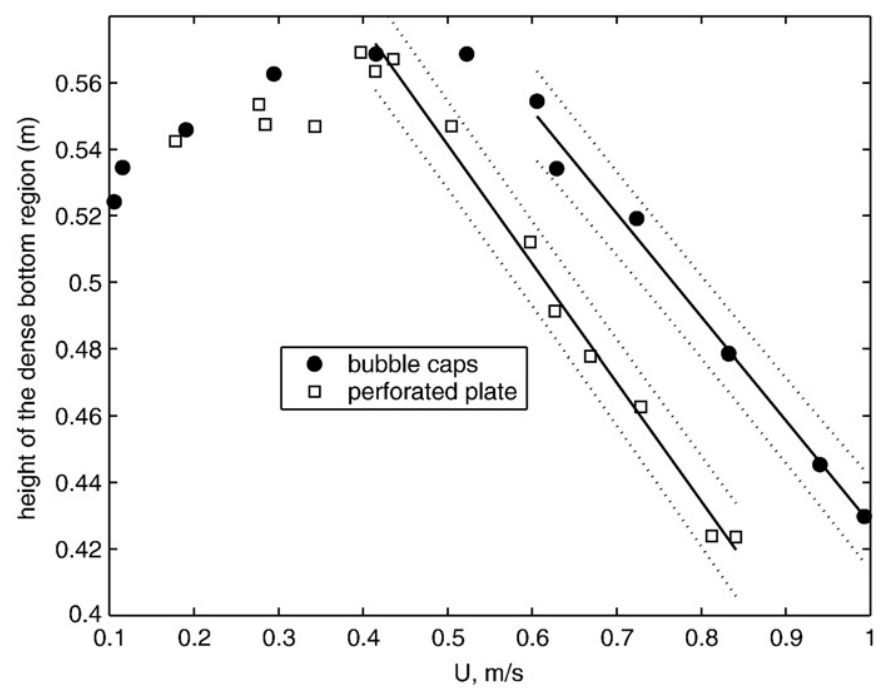

Fig. 11. Height of the dense bed against the superficial gas velocity for the bubble caps and perforated plate distributors deduced by axial pressure drop profiles. $H_{0}=0.5 \mathrm{~m}$. $U_{\text {c,perforated }} \sim 0.46 \mathrm{~m} / \mathrm{s} . U_{\mathrm{c}, \text { caps }} \sim 0.64 \mathrm{~m} / \mathrm{s}$.

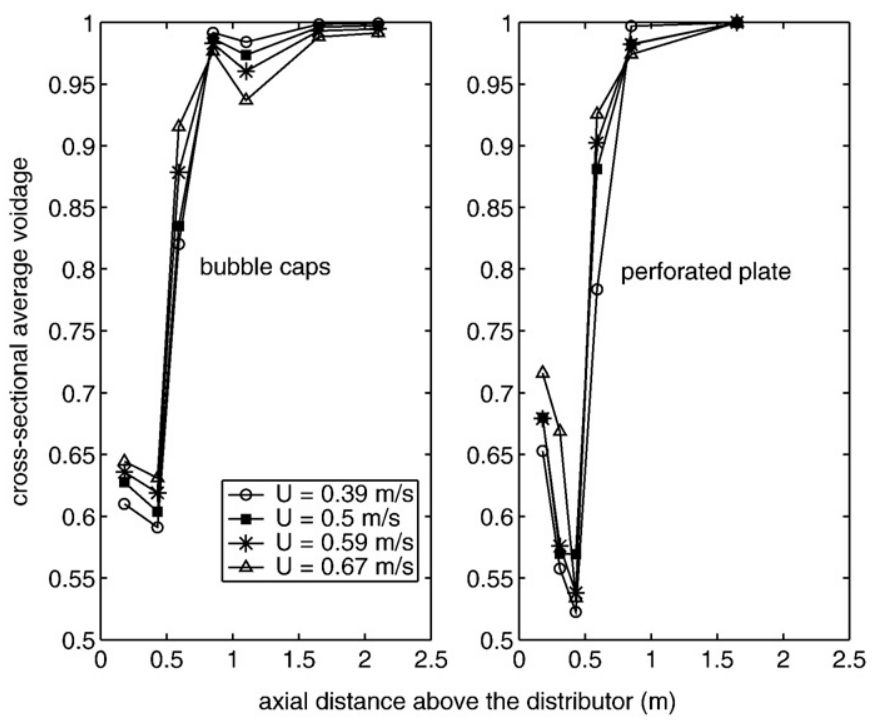

Fig. 12. Time Time-mean cross-sectional average axial voidage profiles from differential pressure measurements at different gas velocities. $H_{0}=0.5 \mathrm{~m}$. $U_{\mathrm{c} \text {, perforated }} \sim 0.46 \mathrm{~m} / \mathrm{s}$. $U_{\text {c,caps }} \sim 0.64 \mathrm{~m} / \mathrm{s}$.

bed to the freeboard is higher for the perforated plate distributor than for the bubble cap distributor at the same superficial gas velocity. Stefanova et al. [28] also found a decrease in the expanded bed height at the onset of turbulent fluidization and explained this decay by the increase of the entrainment and the inability of the solids return system to recirculate all the entrained particles to the bed. The dif ferences found here between the perforated plate and the bubble cap distributor point out an important influence of the distributor in terms of entrainment when operating the bed under transport conditions.

Fig. 12 shows the axial voidage profiles for the two types of distributor for different superficial gas velocities. This was obtained from the differential pressure measurements. It can be observed that for the perforated plate distributor, the voidage in the dense bed is higher than for the bubble cap distributor. The voidage in the dense bed using the bubble cap distributor is also more homogeneous. The high voidage at the axial position closest to the distributor plate, especially for the perforated plate distributor, possibly reflects the jetting effect, and the possible dead zones [9,13]. These observations point out the differences in the jet dynamics and bubble formation in the two different distributors. Rees et al. [29] obtained an experi mental correlation to calculate the mean length of a jet above the orifice of the air distributor, as a function of the diameter of the orifices, the area of the distributor per orifice, the mean velocity of a jet within the orifice and the minimum fluidization velocity. Using this correlation the length of the jet above the perforated distributor used in the experiments is about $6 \mathrm{~cm}$. A very similar value is also obtained using Merry's correlation [30], or the correlation found in Thorpe et al. [25] where the entry zone height is proportional to the orifice spacing. They also reported an equation to calculate the height of the entry zone for tuyere distributors, where horizontal jets are formed. Using this correlation for the bubble cap distributor the height for the entry zone was found to be half of the height of the entry zone for the perforated plate distributor. Therefore, the higher entry zone for the perforated plate distributor explained the higher voidage found close to the distributor. On the other hand, lower voidage observed for both distributors around $z=0.5 \mathrm{~m}$ may be due to the influence of solids re entering the column at axial distances between $0.051 \mathrm{~m}$ and $0.18 \mathrm{~m}$.

\subsection{Radial voidage profiles}

The radial voidage profiles in the bottom region of the bed were measured for both distributors using optical probes at different axial 
a

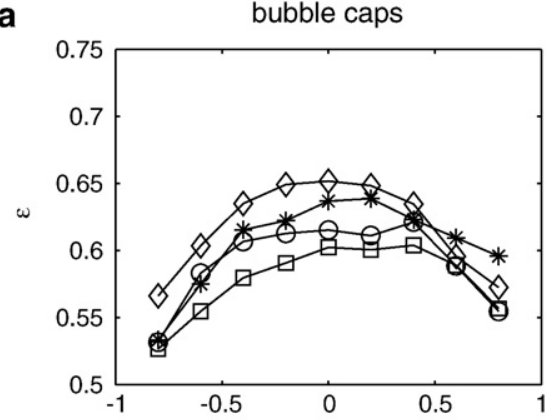

C

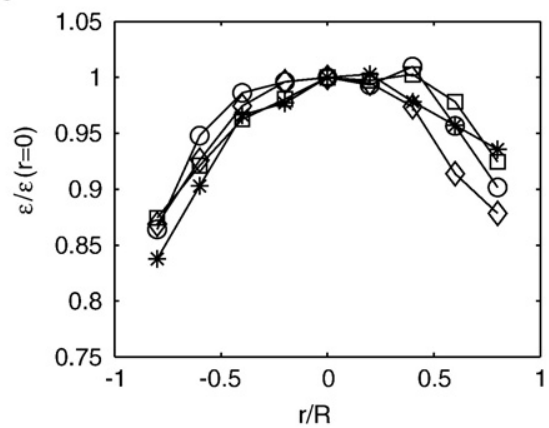

b

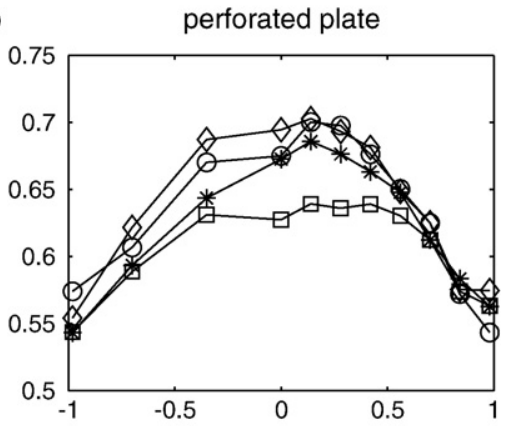

d

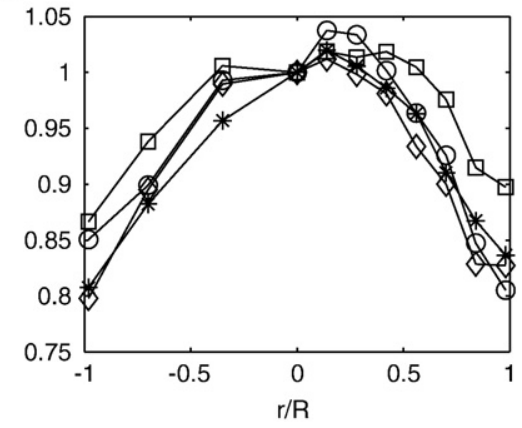

Fig. 13. Radial voidage profiles at $z=0.273 \mathrm{~m}$ above the distributor. $\square U=0.3 \mathrm{~m} / \mathrm{s} \bigcirc U=0.4 \mathrm{~m} / \mathrm{s} * U=0.5 \mathrm{~m} / \mathrm{s} \diamond U=0.6 \mathrm{~m} / \mathrm{s} . H_{0}=0.5 \mathrm{~m} . U_{\text {c,perforated }} \sim 0.46 \mathrm{~m} / \mathrm{s}$. $U_{\text {c,caps }} \sim 0.64 \mathrm{~m} / \mathrm{s}$.

locations. Fig. 13 shows the radial voidage profiles in the column for the two types of distributors at the axial location of $z=0.273 \mathrm{~m}\left(z / H_{0} \sim 0.5\right)$. The initial bed height was $0.5 \mathrm{~m}$ for all the experiments $\left(H_{0} / D \sim 1.7\right)$. Fig. 13a and $\mathrm{b}$ shows that the voidage, $\varepsilon$, is lower for the bubble cap distributor with a flatter $\varepsilon$ radial profile. This is in accordance with the cross sectional average voidage calculated from the differential pressure measurements for this axial position (Fig. 12). Furthermore, voidage measured at the walls for the bubble cap distributor approaches values close to a packed bed, which is also supported experimentally by Guo and Werther [6] in a CFB riser with bubble cap distributor. From the pressure and optical probe measurements, it can be concluded that the cross sectional average voidage is higher for the perforated plate with a lower mean suspension density in the bottom region.
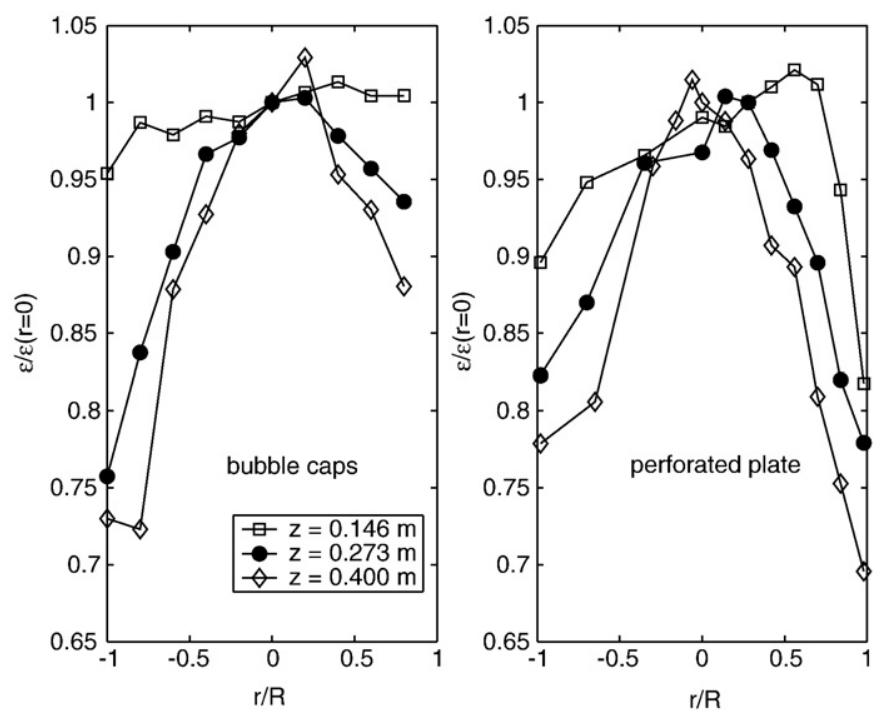

Fig. 14. Radial voidage profiles non-dimensionalized with the voidage at the axis at three different axial positions and a gas velocity $U=0.5 \mathrm{~m} / \mathrm{s} . H_{0}=0.5 \mathrm{~m}$. $U_{\text {c,perforated }} \sim 0.46 \mathrm{~m} / \mathrm{s}$. $U_{\text {c,caps }} \sim 0.64 \mathrm{~m} / \mathrm{s}$.
In Fig. 13c and d, the voidage has been non dimensionalized with the voidage at the axis of the column. It is observed that the radial voidage profiles are quadratic and they present similarity. The maximum value of the voidage is reached in the column axis, and is dependant on the superficial gas velocity.

Fig. 14 shows the radial non dimensionalized voidage profiles near the bottom region at different axial locations for $U=0.5 \mathrm{~m} / \mathrm{s}$. A higher voidage is observed in the centre, while higher solids concentration regions are present at the walls. However, for an axial position closer to the distributor $(z=0.15 \mathrm{~m})$ a fully developed profile is not yet reached, while above $z=0.273 \mathrm{~m}$ quadratic radial profiles are shown. The flat profile observed for the bubble cap distributor at $z=0.15 \mathrm{~m}$ may be due to the central bubble cap being blocked off which pro moted the tendency of bubbles to coalesce away from the axis of the bed. Sobrino et al. [31] also found a flat profile close to the distributor for a bigger column $(D=1.56 \mathrm{~m})$ working with a scaled bubble cap distributor.

Furthermore, it can be concluded that a dilute core and denser annulus structure exists near the bottom region of the bed, as was asserted by other investigators [7]. However, the thickness of the dense phase annulus increases with the height above the distributor and there is a region close to the distributor where the voidage profile is not yet fully developed. In the bottom region there is not a sharp transition from the dilute phase core to the dense phase annulus, but a gradual quadratic decrease of the voidage, i.e., increase of the suspension density is observed from the column axis to the wall. Axial voidage profiles from pressure measurements (Fig. 12) indicate, as others suggested [3], the typical core annulus flow structure with a constant radial solid concentration profile in the core of the bed is more likely to be found higher in the riser.

\section{Conclusions}

The effect of two types of distributors, i.e., perforated plate and bubble cap distributor on the flow structure of the bottom region of a fluidized bed working in the bubbling and turbulent regime has been studied. The perforated plate presented a lower $U_{\mathrm{c}}$ velocity and a higher 
decrease of the dense bed height with increasing the superficial gas velocity. This indicates that the rate of solids transferred from the dense bed to the free board is higher for the perforated plate, and begins at a lower superficial gas velocity. From the pressure measurement results, it is concluded that the solids density near the bottom region is higher for the bubble cap distributors; while a more homogeneous radial structure in terms of voidage is found. The results are in accordance with time mean average voidage obtained with optical probes; whereby, the voidage measured with these probes was also found to be smaller for all radial positions and the profiles obtained were flatter when using the bubble cap distributor. A dilute core and a denser annulus structure was observed in the bottom region of the bed for the two distributors studied. Radial voidage profiles in the dense bed were found to be fitted by a quadratic profile, and presented similarity for different fluidizing velocities.

\section{Nomenclature}

A cross sectional area of the column $\left(\mathrm{m}^{2)}\right.$

$A_{2} \quad$ cross sectional area of the cylindrical section (2) in Fig. 1b $\left(\mathrm{m}^{2)}\right.$

$A_{\text {cap }} \quad$ cross sectional area of the section (3) in Fig. $1 \mathrm{~b}\left(\mathrm{~m}^{2}\right)$

$A_{\text {mesh }} \quad$ cross sectional area of the mesh $\left(\mathrm{m}^{2}\right)$

$A_{\text {orifice }} \quad$ cross sectional area of the orifices of the distributors $\left(\mathrm{m}^{2}\right)$

$C_{\mathrm{d}} \quad$ orifice discharge coefficient ( )

$d_{\text {mesh }} \quad$ mesh opening $(\mathrm{m})$

$d_{\text {orifice }}$ diameter of orifice $(m)$

$g \quad$ gravitational acceleration $\left(\mathrm{m} / \mathrm{s}^{2}\right)$

$\mathrm{H}_{0} \quad$ initial fixed bed height ( $\left.\mathrm{m}\right)$

$H_{\mathrm{b}} \quad$ dense bed height (m)

$K \quad$ flow resistance coefficient ( )

$K_{\text {mesh }} \quad$ flow resistance coefficient of the mesh ( )

$K_{\text {orifice }} \quad$ flow resistance coefficient of orifices ( )

$p \quad$ static pressure $(\mathrm{Pa})$

$R \quad$ column radius $(\mathrm{m})$

$r \quad$ radial coordinate $(\mathrm{m})$

$R e_{\text {mesh }} \quad$ Reynolds number based on diameter opening ( )

$t_{\mathrm{p}} \quad$ thickness of perforated plate $(\mathrm{m})$

$U \quad$ superficial gas velocity $(\mathrm{m} / \mathrm{s})$

$U_{\mathrm{c}} \quad$ superficial gas velocity at which the standard deviation of pressure fluctuations attains a maximum $(\mathrm{m} / \mathrm{s})$

$U_{\text {mesh }} \quad$ gas velocity in the mesh $(\mathrm{m} / \mathrm{s})$

$U_{\mathrm{mf}} \quad$ minimum fluidization velocity $(\mathrm{m} / \mathrm{s})$

$U_{\text {orifice }}$ gas velocity in the orifices $(\mathrm{m} / \mathrm{s})$

$v \quad$ gas velocity $(\mathrm{m} / \mathrm{s})$

$V \quad$ optical probe signal voltage (V)

$V_{0} \quad$ optical probe signal voltage from the black particles bed (V)

$v_{\text {base }} \quad$ higher gas velocity in the component (in the smallest cross cross sectional area) (m/s)

$V_{\mathrm{mf}} \quad$ optical probe signal voltage at minimum fluidization conditions $(\mathrm{V})$

$z \quad$ axial coordinate $(\mathrm{m})$

\section{Subscripts}

c bubble cap distributor

$\mathrm{p} \quad$ perforated plate

1 upward the distributor

2 downward the distributor

\section{Greek letters}

$\Delta p_{\mathrm{d}} \quad$ distributor pressure drop (Pa)

$\Delta p_{\mathrm{b}} \quad$ pressure drop across the bed $(\mathrm{Pa})$

$\varepsilon \quad$ voidage ( )

$\varepsilon_{\mathrm{mf}} \quad$ voidage at minimum fluidization conditions ( )

$\mu_{\mathrm{g}} \quad$ kinematic viscosity of gas (Pa.s)

$\rho_{\mathrm{g}} \quad$ gas density $\left(\mathrm{kg} / \mathrm{m}^{3}\right)$ $\rho_{\mathrm{s}} \quad$ solids density $\left(\mathrm{kg} / \mathrm{m}^{3}\right)$

$\tau \quad$ thickness parameter ( )

\section{Acknowledgements}

The authors wish to thank a fellowship awarded by Carlos III University under the program of mobility of PhD students. The support of NSERC (Natural Science and Engineering Research Council, Canada) is also greatly acknowledged. The authors are grateful for the assistance from Ana Stefanova in running the experiments and the support of CSIRO, Australia, for the bubble cap distributor used in this study.

\section{References}

[1] D. Bai, E. Shibuya, Y. Masuda, N. Nakagawa, K. Kato, Flow structure in a fast fluidized bed, Chemical Engineering Science 51 (1996) 957-966.

[2] D. Bai, A.S. Issangya, J.R. Grace, Characteristics of gas-fluidized beds in different flow regimes, Industrial \& Engineering Chemistry Research 38 (1999) 803-811.

[3] C.M.H. Brereton, J.R. Grace, Microstructural aspects of the behaviour of circulating fluidized beds, Chemical Engineering Science 48 (1993) 2565-2572.

[4] J.Zhou, J.R. Grace, S. Qin, C.M.H. Brereton, C.J. Lim, J. Zhu, Voidage profiles in a circulating fluidized bed of square cross-section, Chemical Engineering Science 49 (1994) 3217-3226.

[5] A. Svensson, F. Johnsson, B. Leckner, Fluid-dynamics of the bottom bed of circulating fluidized bed boilers, in: L. Rubow (Ed.), Proceedings of the 12th International Conference on Fluidized Bed Combustion, ASME, New York, 1993, pp. 887-897.

[6] Q. Guo, J. Werther, Influence of gas maldistribution of distributor design on the hydrodynamics of a CFB riser, Chemical Engineering and Processing 47 (2008) 237-244.

[7] P. Schlichthaerle, J. Werther, Axial pressure profiles and solids concentration distributions in the CFB bottom zone, Chemical Engineering Science 54 (1999) 5485-5493.

[8] Q. Guo, J. Werther, C. Aue-Klett, E.U. Hartge, Flow maldistribution at bubble cap distributor in a plant-scale circulating fluidized bed riser, AIChE Journal 51 (2005) 1359-1366.

[9] D. Geldart, J. Baeyens, The design of distributors for gas-fluidized beds, Powder Technology 42 (1985) 67-78.

[10] Z. Garncarek, L. Przybylski,J.S.M. Boterill, C.J. Broadbent, A quantitative assessment of the effect of distributor type on particle circulation, Powder Technology 91 (1997) 209-216.

[11] J. Werther, Effect of gas distributor on the hydrodynamics of gas fluidized beds, German Chemical Engineering 1 (1978) 166-174.

[12] W. Bauer, J. Werther, The role of gas distribution in fluidized bed chemical reactor design, Chemical Engineering Communications 18 (1982) 137-147.

[13] C.-S. Chyang, Y.-C. Lin, A study in the swirling fluidizing pattern, Journal of Chemical Engineering of Japan 35 (2002) 503-512.

[14] P.N. Rowe, W.M. Stapleton, The behaviour of 12 inch diameter gas-fluidised beds, Transactions of the Institution of Chemical Engineers 39 (1961) 181-187.

[15] D. Sathiyamoorthy, M. Horio, On the influence of aspect ratio and distributor in gas fluidized beds, Chemical Engineering Journal 93 (2003) 151-161.

[16] N. Ellis, H.T. Bi, C.J. Lim, J.R. Grace, Hydrodynamics of turbulent fluidized beds of different diameters, Powder technology 141 (2004) 124-136.

[17] N. Ellis, C.J. Lim, J.R. Grace, X.T. Bi, K.S. Lim, Scale-up Effect on Transition Velocity and Voidage in Turbulent Fluidized Beds, 6th World Congress of Chemical Engineering, Melbourne, Australia, 2001.

[18] A. Stefanova, J.R. Grace, C.J. Lim, X.T. Bi, K.S. Lim, J. Sanderson, Scale-up effect on heat transfer in a fluidized bed near the onset of turbulent fluidization, in: X. Bi, F. Berruti, T. Pugsley (Eds.), Fluidization XII, ECI, New York, 2007, pp. 273-280.

[19] I.E. Idelchik, Handbook of Hydraulic Resistance, CRC Press, 2004.

[20] H. Morikawa, H.T. Bi, C.J. Lim, J.R. Grace, Entrainment from pilot scale turbulent fluidized beds of FCC particles, in: M. Kwauk, J. Li, W.-C. Yang (Eds.), Fluidization X, ECI, New York, 2001, pp. 181-188.

[21] J. Liu, J.R. Grace, X.T. Bi, Simultaneous determination of particle velocity, concentration and flux using a novel multi-functional optical fibre probe: I. Probe development and validation, AIChE Journal 49 (2003) 1405-1420.

[22] J. Liu, J.R. Grace, X.T. Bi, Simultaneous determination of particle velocity, concentration and flux using a novel multi-functional optical fibre probe: II. Hydrodynamic measurements in a high-density circulating fluidized bed, AIChE Journal 49 (2003) 1421-1432.

[23] C.M.H. Brereton, J.R. Grace, The transition to turbulent fluidization, Chemical Engineering Research \& Design 70 (1992) 246-251.

[24] D. Geldart, M.J. Rhodes, From minimum fluidization to pneumatic transport-a critical review of the hydrodynamics, in: P. Basu (Ed.), Circulating Fluidized Bed Technology, Pergamon, Toronto, 1985, pp. 21-31.

[25] R.B. Thorpe, J.F. Davidson, M. Pollitt, J. Smith, Maldistribution in fluidized beds, Industrial \& Engineering Chemistry Research 41 (2002) 5878-5889.

[26] K. Masters, Industrial fluid bed drying: trends and developments, in: O.E. Potter, D.J. Nicklin (Eds.), Fluidization VII, Engineering Foundation, New York, USA, 1992, pp. 545-553.

[27] M. Rhodes, What is turbulent fluidization? Powder technology 88 (1996) 3-14.

[28] A. Stefanova, H.T. Bi, C.J. Lim, J.R. Grace, Heat transfer from immersed vertical tube in a fluidized bed of group A particles near the transition to the turbulent fluidization flow regime, International Journal of Heat and Mass Transfer 51 (2008) 2020-2028. 
[29] A.C. Rees, J.F. Davidson, J.S. Dennis, P.S. Fennell, L.F. Gladden, M.D. Hayhurst, M.D. Müller A.J. Sederman, The nature of the flow just above the perfortaed plate distributor of a gas-fluidised bed, as imaged using magnetic resonance, Chemical Engineering Science 61 (2006) 6002-6015.

[30] J.M.D. Merry, Penetration of vertical jets into fluidised beds, American Institute of Chemical Engineers Journal 21 (1975) 507-510.
[31] C. Sobrino, N. Ellis, M. de Veja, Distributor effect in the bottom region of turbulent fluidized beds: implications to scale-up, in: J. Werther, W. Nowak, K.-E. Wirth, E.-U. Hartge (Eds.), Circulating Fluidized Bed Technology IX, TuTech Innovation GmbH, Hamburg, 2008, pp. 207-212. 